DRW3) may now be identified in more than half of the patients by a relatively simple serological technique.

This work was supported by the Swiss National Science Foundation (grant 3.0407.0.74) and by the Foundation of the Swiss Association for Diabetes.

1 Dausset, J, and Sveigaard, A, HLA and Disease. Copenhagen, Munksgaard, 1977.

2 Jones, E A, et al, Nature, 1975, 256, 650.

3 Histocompatibility Testing. Copenhagen, Munksgaard, in press.

4 Thomsen, M, et al, Transplantation Review, 1975, 22, 126.

(Accepted 3 Fanuary 1978)

Transplantation Immunology Unit and Division of Diabetology, Hôpital Cantonal, Geneva, Switzerland

PH DE MOERLOOSE, MD, assistant

$M$ JEANNET, MD, head of transplantation immunology unit

C BALLY, MD, chief resident

Centre de Transfusion Sanguine and Department of Nutrition and Metabolic Disease, Nancy, France

C RAFFOUX, MD, head of department of immunohaematology

J-P POINTEL, MD, assistant

Department of Paediatrics and Genetics, Hôpital Cantonal, Geneva, Switzerland

P SIZONENKO, MD, assistant professor

\section{Patients' attitudes to measuring their own blood pressure}

Patients with diabetes mellitus commonly monitor their disease by simple urine analysis and adjust their treatment on the basis of these observations. Wilson ${ }^{1}$ has argued that patients with hypertension should measure their own blood pressure at home, but if this concept is widely applied it must be acceptable to those using it. ${ }^{2}$ For several years patients attending our hypertension clinic have measured their own blood pressure, ${ }^{3}$ but while we were aware of the advantages from the doctors' viewpoint we had no definite information on the patients' attitudes. We therefore decided to test their reactions by means of a questionnaire.

\section{Patients, methods, and results}

Ninety-five consecutive patients attending the hypertension clinic were trained to measure their own blood pressure, oral instruction being reinforced by written advice. The equipment used was a Littman Nursescope and an anaeroid sphygmomanometer. All patients had been taking their own blood pressure for some months when they answered the questionnaire.

Ninety-five questionnaires were sent out and $82(86 \%)$ returned. Fortythree of the patients were men and 39 women; their ages ranged from 26-68 years and their occupations from the professional to the unskilled. Twentysix of the patients learnt the technique in under one day, 40 took 2-7 days, and 16 took 7-14 days. Very few were unable to master the technique. Fortythree patients took under five minutes to take their blood pressure both lying and standing, while a further 26 accomplished this in less than 10 minutes. Problems with the apparatus were mainly those of applying the cuff, but with a Velcro strip it could be left rolled up and slipped on the arm without opening. Other difficulties included not hearing the Korotkoff sounds clearly and not being able to inflate the cuff to a sufficient pressure. Thirty-three patients had persuaded a relative or friend to help in taking their blood pressure, and in most cases the assistant dealt both with inflating the cuff and listening with the stethoscope. Twenty-five patients felt encouraged to take their tablets more regularly, particularly when they observed a fall in blood pressure with treatment. Surprisingly, 34 patients were so confident of their readings that they were willing to change their medication on the basis of the figures they obtained. Over half the patients (48) were willing to continue taking their blood pressure at home indefinitely-usually every day. One third of the patients took someone else's blood pressure, usually their spouse's. One patient took a colleague's pressure and on finding it higher than his own pretreatment figure recommended that he saw his doctor for further advice.

The great majority of patients were reassured by taking their blood pressure and most expressed satisfaction from understanding more about the problem for which they were being treated. Some decided to relax consciously when their pressure was high, providing biofeedback.

\section{Comment}

The place of home blood-pressure readings in managing hypertension remains unclear, as the relationship of these readings to clinic records has not been clarified. Burns-Cox et $a l^{4}$ have shown that home blood-pressure measurement is practicable, and our patients clearly found it easy to master the technique and took little time to perform it

We think that home blood-pressure estimation is acceptable to many patients, and suggest that each patient with hypertension should be encouraged to take his or her own blood-pressure at the start of treatment. Measurements should continue for at least three months, by which time the blood pressure should be under control. If the patient wants to continue he should be encouraged to buy his own equipment. Home blood-pressure recording used in this way should improve patient compliance and give greater personal insight into the disorder.

We thank Boehringer Ingelheim for providing the equipment.

1 Wilson, L L, Patient Management, 23 December 1974.

${ }^{2}$ Hatano, S, et al, Bulletin of the World Health Organisation, 1972, 47, 670.

${ }^{3}$ Raftery, E B, Hypertension-Its Nature and Treatment, p 219. CIBA, Horsham, 1974.

4 Burns-Cox, C J, Russell-Ress, J, and Wilson, R S E, British Medical fournal, 1975, 3, 80.

(Accepted 25 November 1977)

Department of Cardiology, Northwick Park Hospital and Clinica Research Centre, Harrow HA1 3UJ

P R WILKINSON, MB, MRCP, medical registrar (now senior medical registrar, Plymouth General Hospital)

E B RAFTERY, MD, FRCP, consultant cardiologist

\section{Ectopic ACTH-secreting tumour of the bronchus and agammaglobulinaemia}

Ectopic ACTH production is one of several well-recognised endocrine manifestations of carcinoma of the bronchus. ${ }^{1}$ I report one such case that is unusual in two respects: firstly, the patient was already receiving corticosteroids for asthma ; and, secondly, he developed agammaglobulinaemia.

\section{Case report}

A 46-year-old man was first admitted to hospital because of asthma. He gave a three-week history of cough, wheezing, and breathlessness, and responded rapidly to corticosteroids and salbutamol by mouth. Respiratory function was normal when tested after discharge. Skin tests gave positive reactions to common allergens, and the results of precipitin tests for aspergillus and avian proteins were negative, as were those of other investigations including plasma electrolytes and protein electrophoresis. He remained well but six months later was seen to be Cushingoid and the dose of prednisolone was reduced to $7 \mathrm{mg}$ daily. Ten months after his first admission he was again admitted to hospital, on this occasion because of severe weakness of one week's duration. He had developed oedema of the legs a few weeks earlier; this had responded to frusemide and had been attributed to a combination of cor pulmonale and the steroids. He was grossly Cushingoid, with striae, hyperpigmentation, a widespread acneiform rash, and oral candidiasis. Plasma concentrations were as follows: sodium $140 \mathrm{mmol}(\mathrm{mEq}) / 1$, potassium $2.5 \mathrm{mmol}(\mathrm{mEq}) / 1$, bicarbonate $34 \mathrm{mmol}(\mathrm{mEq}) / 1$, and urea $8.3 \mathrm{mmol} / \mathrm{l}$ $(50 \mathrm{mg} / 100 \mathrm{ml})$. A chest $x$-ray film showed some prominence of the left hilum but had not changed over the previous two years. Hypokalaemia was attributed to a combination of inadequate potassium supplements and the steroids, and initially with oral and intravenous potassium he improved. Further investigations disclosed glycosuria with a plasma glucose concentration of $32.8 \mathrm{mmol} / 1(591 \mathrm{mg} / 100 \mathrm{ml})$ and he received insulin. Plasma protein electrophoresis now showed agammaglobulinaemia: $\mathrm{IgG}$ was $0.3 \mathrm{~g} / 1$ (normal value $8 \cdot 0-17 \mathrm{~g} / \mathrm{l})$, while $\operatorname{IgA}$ and $\operatorname{IgM}$ were normal. A further chest $x$-ray film showed lingular consolidation, but tomograms were normal. At this stage, because of the chest $x$-ray appearances and his worsening metabolic state, an ectopic ACTH-producing tumour was suspected. The plasma 